\title{
An Extensive Review of Literature: Considering Bone Reaction To Different Agents In Orthodontically Induced Root And Alveolar Resorption
}

Simran Kaur Pawar ${ }^{1}$

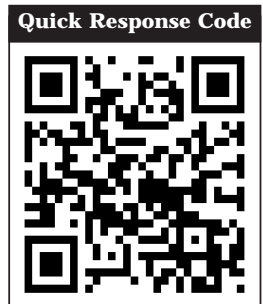

doi: $10.5866 / 2017.9 .10055$

'DAV Dental College,

Yamuna Nagar, India

\section{Article Info:}

Received: J anuary 10, 2017

Review Completed: February 9, 2017

Accepted: March 11, 2017

Available Online: March, 2017 (www.nacd.in)

(c) NAD, 2017 - All rights reserved

Email for correspondence:

simranpawar1992@gmail.com

\begin{abstract}
:
Orthodontically induced root resorption is a common problem in day to day practice. If such root resorption could be prevented, it would be an important contribution toward reducing risk factors in orthodontic treatment. The aim of the review is to focus on different agents which can betherapeutically useful in orthodontic tooth movement. The article reviews various agents inhibiting as well as promoting root and alveolar bone resorption to orthodontic tooth movement based on advanced PUBMED, Cochrane database, Wiley online search of the English language literaturefrom theyear 1951 to present in order to hel p us sel ect the most suitable among them fulfilling the desired criteria of being safe, having less adverse effects, minimal contraindications, rare cross reactions, economically viable, having a scope to be used for successful prognosis and possibly not requiring any special considerations to interpret the results.F orty-nine articles were included in the review, but their interpretation was hindered by the variability in experimental design, magnitude of force applied during tooth movement, and medication regimens. Corticosteroid hormones, parathyroid hormone, and thyroxin have all been shown to increase tooth movement. Bisphosphonates had a strong inhibitory effect.By this review, we concludethat low laser therapy and RGD peptide emerges as the clear winner and can result in better prognosis in orthodontic treatment. These techniques are new and cannot replace the conventional agents as a whole.
\end{abstract}

Key words: Root resorption, I ntegrins, Matrix metall oproteins, Echistatin, Low laser therapy, Doxycycline.

\section{INTRODUCTION}

Orthodontic tooth movement is a biologic responsetowards a mechanical force. The movement is induced by the prol onged application of controlled mechanical forces, which create pressure and tension zones in the periodontal ligament and alveolar bone, causing remodeling of the tooth sockets. ${ }^{1}$ But excessive forces results in orthodontically induced inflammatory root resorption. It has beenconsidered a side-effect of the 
cellular activity associated with the removal of necrotic tissue in an over-compressed periodontal ligament (PDL). ${ }^{2}$ Resorption appears to proceed by the intricate coordination of the processes of attachment to bone, polarized secretion of acid and proteases, and active motility of osteoclasts along the bone substrate. ${ }^{3}$ Cells active in resorption are tightly apposed to the bone surface and form specialized structures at this interface consisting of a highly convoluted membrane called the "ruffled border," surrounded by an actin-rich region, called the "clear zone". ${ }^{4}$ The molecular mechanisms by which osteoclasts attach to bone are not well understood. By analogy to other cells, members of the integrin superfamily of divalent cationdependentadhesion molecules may mediate this interaction. Integrins are heterodimeric glycoproteins of a andb subunits that participate in both cell-substrate and cell-cell interactions. ${ }^{5}$ The superfamily is subdivided into several families defined by the highly disulfide-linked b subunit. These are the VLA/fibronectin b1 receptors, thel eukocyte Leu-CAM / CD18 (b2) receptors, the b3 receptors, and the epithelial cell b4 receptor. The b3 family, also called cytohesin, include the platel et GP IIbll la complex that is essential for platelet aggregation and a vitronectin receptor (avb3).Antibodies recognizing this integrin inhibit bone resorption, and so it may function to anchor resorbing cells to bone. ${ }^{6,7}$ The etiology of root resorption ismost likely a multifactorial problem involvinggenetic predisposition, environmental factors related to the morphology of the roots, and orthodontic treatment-related issues. ${ }^{8-10}$ It has been shown that orthodontic tooth movement can be influenced by general and local pharmacological modulation. ${ }^{11}$ In the present review, the effects of various agents in promoting and inhibiting orthodontically induced root resorption are described.

\section{VARIOUS TECHNIQUES}

\section{RESORPTION INHIBITING AGENT:}

\section{A. Echistatin, an RGD-containing peptide:}

The integrins are a family of cell surface glycoproteins that act as receptors for extracellular matrix (ECM) proteins, or for membrane-bound counter-receptors on other cells. ${ }^{12}$ I ntegrins can bind adhesive ligands and upon this binding results in conformational changes. ${ }^{13}$ Over 20 known integrins recognize the Arg-Gly-Asp (RGD) sequence in their adhesion protein ligands. ${ }^{14}$ The effect of RGD peptides on bone formation and resorption was described in a study, in the mineralizing organ culture system derived from growing rat parietal bones. 0.1-50 ì M GRGDSPK added to bones cultured for four days. ${ }^{15}$ The inhibition of bone formation and resorption by an RGD-containing peptide in a mineralizing organ culture system suggests that integrins have an important role in osteoblast and osteoclast-mediated bone remodeling. A 49 amino acidprotein, disintegrin (echistatin) is a snake venom protein and is one of the smallest natural adhesive ligands with integrin type receptors through Arg-Gly-Asp (RGD) sequence capable of binding to integrins and interfering with integrin function. ${ }^{16}$ The structure of echistatin consists of a core, from this core, an irregular hairpin and the C-terminus protrude these are further stabilized by hydrogen bonds. The role of the alphavbeta3 integrin in bone resorption during orthodontic tooth movement is unknown. However, a study examined the expression of the al phavbeta3 integrin during experimental tooth movement. The expression of alphavbeta3 integrin was examined with two primary antibodies: a polyclonal anti-al pha integrin subunit antibody and a polyclonal antibeta3 integrin subunit antibody. Negative controls were similarly processed but without incubation with primary antibodies. The al phavbeta3 integrin was expressed both by osteoclasts associated with alveolar bone resorption and by odontoclasts associated with root resorption during experimental tooth movement. ${ }^{17}$ It appears that á â3, á â5, and $a_{111}$ â3 are the integrins most reported to be involved in bone function and RGD sequence binding. ${ }^{18}$ Another study tested echistatin RGD peptide effectiveness by local administration ethylene-vinyl acetate (ELVAX), a non-biodegradable, sustainedrel ease polymer adjacent to maxillary molars in rats and shows the feasibility of using ELVAX to deliver integrin inhibitors adjacent to teeth to limit local tooth movement in response to orthodontic forces. ${ }^{19}$ Echistatin may interfere with subtle aspects of integrin-mediated signal transduction important for osteoclasticactivity or migration. ${ }^{11}$ Regardless of themechanism, directevidence for echistatin inhibition of bone resorption invivo makes integrin ligands attractive candidates for thetreatment of diseases associated with increased bone resorption.

\section{B. Low Laser Therapy:}

Numerous studies have shown the effect of 
LLLT at different wavelengths. When LLLT (continuous wave at $830 \mathrm{~nm}$ ) was applied for different set of days such as 9 days for $2.15 \mathrm{~min}$ total $54 \mathrm{j} / \mathrm{cm}^{2}$ or 7 days mid-palatal expansion or 12 days for $3 \mathrm{~min}$ total $35.3 \mathrm{w} / \mathrm{cm}^{2}$ concluded that the acceleration of tooth movement was linked to the stimulatory effect on the process of alveolar bone remodeling in LLLT group, indicated by the significant increases in the amount of bone formation, blood vessels dilatation, and periodontal cell proliferation in the tension side of the dental root as well as the increase in the number and activity of osteoclasts in the opposite pressure side. ${ }^{20,}$ ${ }^{21}$ LLLT (continuous wave GaAlAs at $810 \mathrm{~nm}$ ) in stimulating alveolar boneresorption at the pressure side of the dental root during orthodontic treatment by regulating the activities of osteoclasts through the 84OPG/RANKL/RANK system. ${ }^{22,}{ }^{23}$ LLLT(continuous wave GaAlAs at 780 $\mathrm{nm}$ and 809 $\mathrm{nm}$ ) causes a significant acceleration of the teeth movement, and patients experience a significantly lower degree of pain level in teeth that received LLLT during the orthodontic treatment. ${ }^{24,25}$ Two studies of LLLT (continuous wave GaAIAs at $808 \mathrm{~nm}$ at $0.71 \mathrm{~J} / \mathrm{cm}^{2}$ and $4.98 \mathrm{~J} / \mathrm{cm}^{2}$ respectively) significantly increases the remodeling and the turnover rate of the connective tissues surrounding the root during tooth movement in rats. ${ }^{21,26}$ These results indicate that LLLT application at the range of $830 \mathrm{~nm}$ wavelength is an effective modality in stimulating the remodeling activity and the regenerative capability of the connective tissues around the dental root. ${ }^{27}$ Similar results were concluded with light-emitting diode-mediated-photobiomodulation therapy (LPT), on the rate of orthodontic tooth movement (TM) and orthodontically induced root resorption, in rats. Wistar rats were separated into two groups (control and LPT), and $50 \mathrm{CN}$ of force was applied. The surface area of root resorption lacunae was measured histomorphometrically using digital photomicrographs. Statistical analysis showed significant differences between two groups after treatment/observation period ( $p=0.017$ ). Statistically significant inhibition of root resorption with LPT was determined $(p \varangle 0.001)$ on the TM side showing that LPT method has the potential of accelerating orthodontic tooth movement and inhibitory effects on orthodontically induced resorptive activity. ${ }^{28}$

\section{Doxycycline and L-thyroxine:}

A series of studies has been published describing anti-inflammatory properties of tetracyclines unrelated to their antimicrobial effect. ${ }^{29-31}$ Among the tetracyclines, doxycycline (DC) has been shown to reduce the total number of osteoclasts and prevent root resorption and alveolar bone loss in rats. ${ }^{32,33} \mathrm{In}$ an experimental study, various factors were compared between DC-treated and non-DC-treated animals. The results reveal ed a significant reduction in root resorption, the number of odontoclasts, osteoclasts, mononuclear cells on the root surface, and TRAP-positive cells on the root and bone for the DC-administered group. The absolute alveolar bone area was greater, whereas the distance between the first and second molars did not differ between groups. ${ }^{34}$ Tetracyclines, as anti-resorptive drugs, may act similarly to bisphosphonates and primarily affect osteoclast function. ${ }^{35,}{ }^{36}$ Another study was done to histologically evaluate and compare the effects of the systemic administration of $L$-thyroxine (TX) and doxycycline (DC) on orthodontically induced root resorption. Histomorphometric analysis of root resorption expressed as a percentage, showed that the average relative root resorption affecting the maxillary molars on the TM side was less in the DC groups as compared to control. ${ }^{37} \mathrm{H}$ owever, it was demonstrated in a study that although the level of parathyroid hormone in serum plays an important role in the regulation of the resorptive activity in bone, a change in serum calcium level is a determining factor for root resorption. ${ }^{38}$ In addition to parathyroid hormone, bone resorptive activity is also regulated by L-thyroxine. ${ }^{39,40}$ Thyroid hormone plays a crucial rolein normal growth and devel opment of vertebrate bones. ${ }^{41}$ The administration of high doses of TX has been shown to increase bone resorption. ${ }^{42}$ Another study reported that thyroid hormones increase osteoclastic bone resorption by stimulation of prostaglandin, especially prostacyclin synthesis. ${ }^{43}$ The effects of TX on root resorption are still controversial.

\section{Odanacatib:}

Odanacatib (Pinn; codenamed MK-0822) is an investigational treatment for osteoporosis and bone metastasis. ${ }^{44}$ It is an inhibitor of cathepsin $\mathrm{K}$ an enzyme involved in bone resorption. ${ }^{45} \mathrm{~A}$ study was done to investigate the effect of local administration of odanacatib (ODN) on orthodontic root resorption and the status of alveolar bone metabolism in rat molars. The total volume of the root resorption craters of the $60 \mathrm{~g}$-NS (normal saline) group was 
higher than in the 60 g-ODN group and the control group. The results of tartrate-resistant acid phosphatase-positive (TRAP +) numbers showed that there was no difference between the $60 \mathrm{~g}$-NS group and the $60 \mathrm{~g}$-ODN group. The expression of cathepsin K was decreased significantly in the 60 g-ODN group. These results indicate that ODN reduces orthodontics-induced external root resorption and increases alveolar bone metabolism. This may be because ODN inhibits the activity of odontoclasts, but maintains the quantity ofodontoclasts and enhances bone formation. ODN promotes local alveolar bone metabolism but does not affect systemic bone metabolism. ${ }^{46}$

\section{E. Histamine receptor blocker:}

Although histamine was shown to be involved in bone remodeling, a study was done to determine the effects of cetirizine, an $\mathrm{H}(1)$ receptor antagonist, on bone model ing processes during orthodontic tooth movement. ResultsshowedCetirizine decreased the amount of tooth movement from day 28 onward ( $P$ $<0.01$ ), and it also decreased osteoclast volume density ( $P<0.001$ ). An increase in alveolar bone volume density was observed in the cetirizine group ( $P \varangle 0.01$ ) compared with the appliance-only group. Concluded Cetirizine influences bone modeling, mainly by inhibiting bone resorption. Therefore, $\mathrm{H}(1)$ receptor antagonists could interfere with orthodontic treatment. ${ }^{47}$ Another study made acomparison between three possible osteoporotic treatments in theprevention of glucocorticoidinduced alveolar bone loss. Result presented histopathologically the glucocorticoid group showed wide medullary cavities with wide osteocytic lacunae. The DEXA revealed asignificant reduction in the bone mineral density in all experimental groups compared to the control group.Concluded,the administration of $\mathrm{H} 1$ or $\mathrm{H} 2$ receptor antagonists separately could minimize the alveolar bone loss caused by the administration of glucocorticoids while concomitant administration of both $\mathrm{HI}$ and $\mathrm{H} 2$ receptor antagonists deteriorated the bone condition. 48

\section{F. LithiumChloride:}

Studies have demonstrated the ability of Lithium Chloride ( $\mathrm{LiCl}$ ) to enhance bone formation via the canonical Wnt/â-catenin signaling pathway. $\mathrm{LiCl}$ has been used for decades for the treatment of bipolar disorder by increasing â-catenin signaling through the inhibition of GSK-3â. ${ }^{49,50}$ The canonical
Wnt/â-catenin pathway increases bone mass in several ways, including the renewal of stem cells, stimulation of preosteoblast replication, induction of osteogenesis and inhibition of osteoblast and osteocyte apoptosis. ${ }^{51}$ Since orthodontic tooth movement involves the repeated process of alveolar bone remodeling, $\mathrm{LiCl}$ has the potential to affect tooth movement during orthodontic treatment by affecting the process of bone formation. ${ }^{52,53}$ Osteoclasts are involved in resorbing the alveolar bone at pressure areas, which appear in the direction of the applied force, while osteoblasts are involved in new bone formation at tension areas, on the opposite side. ${ }^{52,54}$ Studies have shown high levels of â-catenin in osteoblasts form excessive bone substances with limited osteodlasts. ${ }^{55,56}$ In a study, lithium chloride ( $\mathrm{LiCl}$ ), a Wht signaling activator, was examined to determine its effect on root resorption, rats were randomly allocated into the experimental group (EG) and control group (CG). A $50 \mathrm{~g}$ force was applied. The outcomes were analyzed using ANOVA. The average distance measured in the CG was slightly higher than in the EG. Root resorption craters were observed in the groups following the experiment. The mean root resorption area ratio of CG was significantly greater than EG $(\mathrm{P}<0.05)$. Results of the present study indicate that $\mathrm{LiCl}$ can attenuate orthodontically induce root resorption during orthodontic tooth movement. The effect of $\mathrm{LiCl}$ on tooth movement is insignificant. ${ }^{57}$

\section{G. Bisphosphonates:}

Bisphosphonates (BSP) bind strongly to the bone mineral hydroxyapatite and inhibit bone resorption. ${ }^{58}$ They target calcified tissues, in which they are internalized selectively by boneresorbing osteoclasts. ${ }^{59,} 60$ Once internalized, BSPinhibits the ability of osteoclasts to resorb bone by mechanisms that interfere with cytoskeletal organization and formation of the ruffled border, and this leads to cell death by apoptosis. ${ }^{61,62} \mathrm{~A}$ study was conducted to investigate the effect of BSP on orthodontic tooth movement and root resorption in mice. A force of 10 $\mathrm{g}$ was delivered BSP (2 microg/20 micro L) was injected daily into a local site adjacent to the upper molar. After 12 days, the results suggested that BSPs might have an inhibiting effect on root resorption during orthodontic tooth movement in humans and that they may interrupt tooth movement in orthodontic patients undergoing treatment, thus altering the outcome of treatment. ${ }^{63}$ Another study was done to examine the effect of the 
local administration of clodronate on orthodontic tooth movement. The number of osteoclasts on the clodronate-injected side was significantly less $(P<$ 0.01 ) than on the control side. The results suggested that localized use of clodronate could be a useful therapeutic adjunct in orthodontic treatment. ${ }^{64}$ One more study was done to examine the effect of topical administration of a BSP (risedronate), The topical administration of risedronate caused a significant and dose-dependent reduction of tooth movement after the orthodontic force was applied. I n the second experiment, the spring was then removed, and administration of risedronate was begun. Thetopical administration of risedronate inhibited relapse of the tooth in a dose-dependent manner. The results suggested that topical application of risedronatemay be helpful in anchoring and retaining teeth under orthodontic treatment. ${ }^{65}$ To investigate the effects of systemically administered alendronate, one of the most potent BSPs, on alveolar bone resorption and angiogenesis in rats was subjected to experimental periapical lesions over two time periods with pulp chambers opened. The experimental group received daily subcutaneous injections of alendronate at a dose of $0.25 \mathrm{mg} \mathrm{kg}(-1)$, whereas the control group received only the saline vehicle. After 2 or 4weeks, the result showed overall periapical bone loss area and the number of TRAP-positive cells (osteoclasts) were significantly decreased at 2 and four weeks, respectively, after daily subcutaneous injection of alendronate compared with the control group $(\mathrm{P}<$ 0.05). Concluded administration of alendronate to rats might inhibit alveolar bone resorption associated with periapical disease, which might not lead to impairment of angiogenesis. ${ }^{66}$

\section{RESORPTION PROMOTING AGENT:}

\section{a) Cyclosporine:}

The effect of CSA on thehuman bone is still not clearly defined. Some studies in transplant patients suggested that CsA causes bone loss; however, it is difficult to be certain because these patients are usually treated with a combination of drugs, other than CSA, including glucocorticoids, which also could stimulate bone resorption. ${ }^{67}$ On the other hand, the ability of CsA to inhibit the production of inflammatory cytokines associated with the T-cells activation could provide a direct protective effect against bone resorption. This protective effect was demonstrated in vivo, as CSA prevented bone loss that usually occurs in association with arthritis in rats. Moreover, CsA can directly inhibit in-Vitro bone resorption induced by the application of active mediators such as interleukin-1 (IL-1), prostaglandin E2 (PGE2), 1,25-dihydroxy-vitamin D3, and parathyroid hormone. ${ }^{68}$ The variation in the effect of CSA in the bone density could be related to the drug dose level. A study found that only a high oral dose of CsA, around $30 \mathrm{mg} / \mathrm{kg}$, would decrease the bone volume in both growing andadult rats. ${ }^{69}$ Moreover, gender-related differences in the effect of CSA on the bone tissues were also suggested. It has been reported that CSA stimulates bone formation in female rats while it increases bone resorption in male rats, even though, neithersex hormones nor gonadectomy was found to modulate the CsA effect on osseous tissues. ${ }^{70}$ Therefore, it could be postulated that the decrease in male rats' mandibular bonemass following CsA therapy, as reported in the literature, is related to the 46 animal gender. ${ }^{71}$ Accordingly, the effect of CsA on thealveolar bone is controversial. CSA therapy could have a suppression effect on alveolar bone mass, specifically on osteoid formation around the molar regions. ${ }^{72}$ However, others found that use of immunosuppressive levels of CSA has no effect on alveolar bone homeostasis in rats'healthy periodontium tissues. ${ }^{73} \mathrm{~A}$ study was done wheretwo groups, were fed with $8 \mathrm{mg} / \mathrm{kg}$ CsA (experiment) or mineral oil (control) daily. Results showed significantly larger changes in intermolar distances after orthodontic force application in the CsA group at days 3 and 12 when compared with the control group. The inter-radicular dental alveolus of CSAfed rats was osteopenic. Significantly increased TRAP-5b serum level was noted in the CsA group when compared with the control group. Suggested that CSA enhanced the rate of orthodontic tooth movement. The osteopenia and the increased osteoclastic activity could be the underlying factors. ${ }^{74}$

\section{b) Glucocorticosteroids:}

Corticosteroids are commonly used to treatmany different diseases because of their antiinflammatoryeffect. ${ }^{75} \mathrm{~A}$ study was done to investigate the effect of different courses of glucocorticosteroid treatment on orthodontically induced root resorption. Rats were divided into three groups: control, acute and chronic. Acuteand chronic groups received corticosteroid treatment $(5 \mathrm{mg} / \mathrm{kg} /$ day of methylprednisolone) for 3 and seven weeks, respectively, while no pharmacological treatment was performed in the control group. A 
histopathological based assessment method for the percentage of root resorption was performed. The results revealed that the percentage of root resorption is increased significantly in steroidtreated groups compared to control group, ther efore; steroid administration will influence the occurrence of root resorption. ${ }^{76}$

\section{DISCUSSION}

Root resorption is a common feature during orthodontic tooth movement. Histological studies have reported that root resorption occurs in $90 \%$ of teeth that havebeen moved orthodontically. ${ }^{77,78}$ Root resorption is considered to be the result of an inflammatory reaction; thus, certain researchers call this process 'orthodonticallyinduced inflammatory root resorption'. ${ }^{79}$ Studies have confirmed that orthodonticallyinduced root resorption is a part of the hyaline (sterile necrosis) zone elimination process. The first cells to be involved in the removal of necrotic tissue are macrophage-like cells, which may be activated by signals from sterile necrotic tissue, as a result of orthodontic force application. ${ }^{80}$, ${ }^{81}$ Osteoclasts and odontoclasts are implicated in the root resorption process. ${ }^{82} \mathrm{~A}$ variety of drugs that have been reported tolimit the inflammation process induced by orthodontic biomechanics tend to suppress root resorption and hinder the movement of teeth by interfering with the resorption process on the pressure side. ${ }^{83,84}$ In many experimental TM studies, non-standardized or unclearly explained springs or el astics hadbeen used as the force del ivery system. According to Ren $Y$ et al standardized cl osed coil springs were preferred to produce a constant and continuous force over the experimental period.In previous research, testing materials or pharmacological agents have been administered systemically through the drinking water of the experimental animals. ${ }^{85,86}$ The implantation of miniosmotic pumps offers a controlled way of continuous drug administration. ${ }^{87}$ Therefore, pump implantation should, optimally, precede orthodontic appliance insertion by at least oneday to establish a steady DC and TX serum level by the time of force application. The measurement of root resorption craters was adopted from Talic N f et al who used percentages instead of total resorption area in square micrometers. ${ }^{88}$ Thus, the percentage of resorption areas to root was considered to be appropriatefor assessment of root resorption instead of total resorption area.According to $\mathrm{Yu}$ Wang et al.LiCl attenuates orthodonticallyinduced root resorption during orthodontic tooth movement. The effect of $\mathrm{LiCl}$ on tooth movement is insignificant. ${ }^{89}$ The topical application of bisphosphonates, which are potent bone resorption inhibitors capable of inducing osteoclast apoptosis, has been reported to suppress orthodontic tooth movement. ${ }^{90-93}$ Kehoe MJ et al. suggested that LLLT group in the first experiment was attributed to the change in tissue absorption of the laser energy caused by the angle at which the laser beam struck the root surfaces. Decreased reflection of laser light and subsequently increased available energy for tissue absorption are expected when the root surface is exposed to a perpendicular laser beam. ${ }^{94}$ Moreover, the possible diminution of laser energy absorption at deeper aspects of the root surface may also explain the different tissue responses between the root surfaces in the LLLT group, because the energy of the laser beam decreases as the laser light passes through the tissue. ${ }^{95}$ The osteopenia and the increased osteoclastic activity could bethe underlying factors. ${ }^{96}$ In steroid study, acute corticosteroid ingestion reduces bone turnover. Therefore, orthodontic treatment might best be postponed until a time the patient is free of the drug. Chronic steroid ingestion leads to an increased biological reaction to mechanical perturbation indicating that the orthodontic force level should be reduced and controlled more frequently in patients on chronic steroid treatment. ${ }^{97}$

\section{CONCLUSION}

Orthodontic treatment would not be possible without the fact that teeth root surfaces are more resistant to resorption than the opposing alveolar bone. The presence of a viable cementum layer covering the root surface may primarily underliethe resistance of the root to resorption.By our review we can conclude that in low laser therapy more is the energy absorption of the laser treatment by the target tissue, more is the cementum forms over the root surface before applying the orthodontic force, and ultimately, the less OITRR occurs on that surface as compared to doxycycline and bisphosphonates. Whereas, echistatin mechanism can also bring success to the orthodontic treatment by interfering with subtle aspects of integrinmediated signal transduction important for osteoclastic activity or migration. However, other treatment modalities are also applicable as they having their limitations. Glucocorticoids and lithium are bone-resorbing agents resulting failure of TM. 
Researchesand further clinical trials arestill needed to be doneto evaluate the most valuable and successful agent in the stream of orthodontic tooth movement.

\section{ABBRE VATIONS}

- $\quad$ anti-ligand-induced binding site (LIBS) antibodies

- Arg-Gly-Asp (RGD)

- $\quad$ ethylene-vinyl acetate (ELVAX)

- low-level laser therapy (LLLT)

- rapid palatal expansion (RPE)

- light-emitting diode-mediatedphotobiomodulation therapy (LPT)

- tooth movement (TM)

- doxycycline (DC)

- $\quad$ ormal saline (NS)

- tartrate-resistant acid phosphatase (TRAP)

- $\quad$ L-thyroxine (TX)

- odanacatib (ODN)

- dual-energy X-ray absorptiometry (DEXA)

- Lithium Chloride ( $\mathrm{LiCl}$ )

- Bisphosphonates (BSP)

- Cyclosporine A (CsA)

\section{REFERENCES}

1. Muthukumarkarthi, Gobichettipalyam, J agtheeswaranAnbuslevan, Kullampalyam Palanisamy Senthilkumar, Senthilkumar Tamizharsi, Subramani Raja, and Krishnan Prabhakar. NSAIDs in orthodontic tooth movement. J Pharm Bioallied Sci 2012; 4 Suppl 2:304-6.

2. Reitan $\mathrm{K}$. The initial tissue reaction incident to orthodontic tooth movement. Acta Odontologica Scandinavica 1951; 9 Suppl 6:44.

3. Kanehisa J and J NM Heersche. Osteoclastic bone resorption: in vitro analysis of the rate of resorption and migration of individual osteoclasts. Bone 1988; 9:73-9.

4. Values, G. Cellular biology and biochemical mechanism of bone resorption. Clin Orthop Relat Res 1988; 228:239-71.

5. Hynes RO. Integrins: a family of cell surface receptors. Cell 1987; 48:549-54.

6. Chambers TJ , Fuller K, Darby J A, Pringel J AS, Horton MA: Monoclonal antibodies against osteoclasts inhibit bone resorption in vitro. Bone Miner 1986; 1:127-35.

7. Davies J, Warwick J, Totty N, Philp R, Horton M. The osteoclast functional antigen, implicated in the regulation of bone resorption, is biochemically related to the vitronectin receptor. J Cell Biol 1989; 109:1817-26.

8. Abass SK, Hartsfield J. Orthodontics and external apical root resorption. Semin Orthod 2007; 13 (4):246-56.

9. Abuabara A. Biomechanical aspects of external root resorption in orthodontic therapy. Med Oral Patol Oral Cir Bucal 2007; 12(8):610-3.

10. Bartzela T, Turp J C, Motschall E, Maltha J C. Medication effects on the rate of orthodontic tooth movement: $A$ systematic literature review. Am J Orthod Dentofacial Orthop 2009; 135(1):16-26.

11. Hynes RO. Integrins: versatility, modulation, and signaling in cell adhesion. Cell 1992; 69(1):11-25.

12. Calvete $\mathrm{J} \mathrm{J}$. Clues for understanding the structure and function of a prototypic human integrin: the platelet glycoprotein II b/l Ila complex. Thromb Haemost 1994; 72(1):1-15

13. Ruoslahti E. RGD and other recognition sequences for integrins. Annu Rev Cell Dev Biol 1996; 12:697-715.

14. Kloczewiak M, Timmons S, Lukas TJ , Hawiger J E. Platelet receptor recognition site on human fibrinogen. Synthesis and structure-function relationship of peptides corresponding to the carboxy-terminal segment of the gamma chain. Biochemistry 1984; 23(8):1767-74.

15. Gronowicz GA, Derome ME. Synthetic peptide containing Arg-Gly-Asp inhibits bone formation and resorption in a mineralizing organ culture system of fetal rat parietal bones Authors. J Bone Miner Res 1994; 9(2):193-201.

16. Gould RJ , Polokoff MA, Friedman PA, Huang TF, Holt J C, Cook JJ and Niewiarowski S. Proc Soc Exp Biol Med 1990; 195:168-71.

17. Talic N1, Evans CA, Daniel J C, George A, Zaki AM. Immunohistochemical localization of alphavbeta3 integrin receptor during experimental tooth movement. AmJ Orthod Dentofacial Orthop 2004; 125(2):178-84.

18. Schaffner P \& Dard M. CMLS: Cell Mol LifeSci 2003; 60:119.

19. C Dolce, A Vakani, L Archer, JA Morris-Wiman, LS. Holliday. Effects of Echistatin and an RGD Peptide on Orthodontic Tooth Movement. J DR 2003; 82(9):682-6.

20. Miyauchi A, Alvarez J, Greenfield EM, Teti A, Grano M, Colucci S, Zambonin-Zallone A, Ross FP, Teitel baum SL, Cheresh D, Hruska KA. Binding of osteopontin to the osteoclast integrin alpha-v-beta-3. Osteoporosis Int 1993; 3:132-135.

21. Kawasaki K, Shimizu N. Effects of low-energy laser irradiation on bone remodeling during experimental tooth movement in rats. Lasers Surg Med 2000; 26(3):282-91.

22. Genc G, Kocadereli I, Tasar F, Kilinc K, EI S, Sarkarati B. Effect of low-level laser therapy (LLLT) on orthodontic tooth movement. Lasers Med Sci 2013; 28(1):41-7.

23. Kim YD, Kim SS, Kim SJ, Kwon DW, J eon ES, Son WS. Low-level laser irradiation facilitates fibronectin and collagen type I turnover during tooth movement in rats. Lasers Med Sci 2010; 25(1):25-31. 
24. Fujita S, Yamaguchi M, Utsunomiya T, Yamamoto H, Kasai $\mathrm{K}$. Low-energy laser stimulates tooth movement velocity via expression of RANK and RANKL. Orthod Craniofac Res 2008; 11(3):143-55.

25. Yamaguchi M, Hayashi M, Fujita S, Yoshida T, Utsunomiya $T$, Yamamoto $\mathrm{H}$, et al. Low-energy laser irradiation facilitates the velocity of tooth movement and the expressions of matrix metalloproteinase-9, cathepsin K, and alpha(v) beta(3) integrin in rats. Eur J Orthod 2010; 32(2):131-9.

26. Franzen TJ, Zahra SE, El-Kadi A, Vandevska Radunovic $V$. The influence of low-level laser on orthodontic relapse in rats. Eur J Orthod 2015; 37(1):111-7.

27. Saito S, Shimizu N. Stimulatory effects of low-power laser irradiation on bone regeneration in mid-palatal suture during expansion in the rat. Am J Orthod Dentofacial Orthop 1997; 111(5):525-32.

28. Mahmoud Abdulsalam Alsulaimani. Titleofpreprint/ era.library.ualberta.ca/files/c8623hx76r/ Alsulaimani_Mahmoud_A_201512_PhD. Accessed may 2015.

29. Ekizer A, Uysal T, Guray E et al. Effect of LED-mediatedphotobiomodulation therapy on orthodontic tooth movement and root resorption in rats. Lasers Med Sci 2015; 30:779.

30. Golub L M et al. Minocycline reduces gingival collagenolytic activity during diabetes. Preliminary observations and a proposed new mechanism of action. J Periodontal Research 1983; 18:516-26.

31. Golub L M et al. Tetracyclines inhibit tissue collagenase activity. A new mechanism in the treatment of periodontal disease. J Periodontal Research 1984; 19:651-5.

32. Golub L M et al. Further evidence that tetracyclines inhibit collagenase activity in human crevicularfluid and from other mammalian sources. J Periodontal Research 1985; 20:1223.

33. Golub LM, MCNamara TF, D'Angelo G, Greenwald RA, Ramamurthy NS. A non-antibacterial chemically-modified tetracycline inhibits mammalian collagenase activity. J DR 1987; 66:1310-4.

34. Grevstad HJ. Doxycycline prevents root resorption and alveolar bone loss in rats after periodontal surgery. Scandinavian J D R 1993; 101:287-91.

35. Grevstad HJ, Boe OE. Effect of doxycycline on surgically induced osteoclast recruitment in the rat. European J Oral Sci 1995; 103:156-9.

36. Maria Mavragani, Pongsri Brudvik, Knut Andreasselvin. Orthodontically induced root and alveolar bone resorption: inhibitory effect of systemic doxycycline administration in rats. 2005; 215-25.

37. AT Vernillo, BR Rifkin. Effects of Tetracyclines on Bone Metabolism. 1998; 156-62.

38. Asli Baysal, Tancan Uysal, Saim Ozdamar, Bulent Kurt, Gokmen Kurt, Omer Gunhan. Comparisons of the effects of systemic administration of L-thyroxine and doxycycline on orthodontically induced root resorption in rats. 2010; 124:496-504.
39. Engstrom C, Granstrom G, Thilander B. Effect of orthodontic force on periodontal tissue metabolism. A histologic and biochemical study in normal and hypocalcemic young rats. Am J Orthodontics Dentofacial Orthopedics 1988; 93:486-95.

40. Tapp E. The effects of hormones on bone in growing rats. The J ournal of Bone and J oint Surgery 1966; 48:526-31.

41. Persson EC, Engstrom C, Thilander B. The effect of thyroxine on craniofacial morphology in the growing rat. Part I: a longitudinal cephalometric analysis. European J Orthodontics 1989; 11:59-66.

42. Vazquez-Landaverde LA, Rojas-Huidobro R, GallegosCorona MA, Aceves C. Periodontal 52-deiodination on forced-induced root resorption-the protective effect of thyroid hormone administration. European J Orthodontics 2002; 24:363-9.

43. Adams $P$, J owsey J. Bone and mineral metabolism in hyperthyroidism: an experimental study. Endocrinology 1967; 81:735-40.

44. Klaushofer K, et al. The Bone-resorbing activity of thyroid hormones is related to prostaglandin production in cultured neonatal mouse calvaria. J Bone and Mineral Research 1989; 4:305-12.

45. Le Gall CL, BonnelyeE, Clezardin P. Cathepsin K inhibitors as treatment of bone metastasis. Current Opinion in Supportive and Palliative Care 2008; 2(3):218-22.

46. Gauthier J Y, Chauret N, Cromlish W, et al. The discovery of odanacatib (MK-0822), a selective inhibitor of cathepsin K. Bioorg Med Chem Lett 2008; 18(3):923-8.

47. Wei XX, Chu J P, Zou YZ, Ru N, Cui SX, Bai YX. Effect of odanacatib on root resorption and al veolar bone metabolism during orthodontic tooth movement. Genet Mol Res 2015; 14(4):17972-81.

48. Meh A, Sprogar S, Vaupotic T, Cor A, Drevenšek G, Marc J , Drevensek M. Effect of cetirizine, a histamine [H(1)] receptor antagonist, on bone modeling during orthodontic tooth movement in rats. Am J Orthod Dentofacial Orthop 2011; 139(4):323-9.

49. Ezzat BA, Abbass MM.The ability of $\mathrm{H} 1$ or $\mathrm{H} 2$ receptor antagonists or their combination in counteracting the glucocorticoid-induced alveolar bone loss in rats.J Oral Pathol Med 2014; 43(2):148-56.

50. Hedgepeth CM, Conrad LJ , Zhang J, Huang HC, Lee VM and Klein PS. Activation of the Wnt signaling pathway: a molecular mechanism for lithium action. Dev Biol 1997; 185:82-91.

51. Schou M. Lithium treatment at 52. J Affect Disord 2001; 67:21-32.

52. Krishnan V, Bryant $\mathrm{HU}$, and MacDougald OA. Regulation of bone mass by Wnt signaling. J Clin Invest 2006; 116:1202-9.

53. Reitan K. Clinical and histologic observations on tooth movement during and after orthodontic treatment. Am J Orthod 1967; 53:721-45. 
54. Rygh P. Ultrastructural changes in tension zones of rat molar periodontium incident to orthodontic tooth movement. Am J Orthod 1976; 70:269-81.

55. Yoshimatsu $M$, Kitaura $\mathrm{H}$, Fujimura $\mathrm{Y}$, Kohara $\mathrm{H}$, Morita $\mathrm{Y}$, Eguchi $\mathrm{T}$ and $\mathrm{Y}$ oshida $\mathrm{N}$. I nhibitory effects of IL-12 on experimental tooth movement and root resorption in mice. Arch Oral Biol 2012; 57:36-43.

56. Holmen SL, Zylstra CR, Mukherjee A, Sigler RE, Faugere MC, Bouxsein ML, Deng L, Clemens TL and Williams BO: Essential role of beta-catenin in postnatal bone acquisition. J Biol Chem 2005; 280:21162-8.

57. Hill TP, Spater D, Taketo M M, Birchmeier W and Hartmann C. Canonical Wnt/beta-catenin signaling prevents osteoblasts from differentiating into chondrocytes. Dev Cell 2005; 8:727-8.

58. Yu Wang, Shang Gao, Huan J iang, Peng Lin, XingfuBao, Zhimin Zhang, Min Hu. Lithium chloride attenuates root resorption during orthodontic tooth movement in rats 2013; $15: 468-72$

59. J ung A, Bisaz S, Fleisch $H$ : The binding of pyrophosphate and two diphosphonates by hydroxyapatite crystals. Calcified Tissue Research 1973; 11:269-80.

60. Sato $M$, et al. Bisphosphonate action. Alendronate localization in rat bone and effects on osteoclast ultrastructure. J Clinical Investigation 1991; 88:2095-105.

61. Frith J C, Monkkonen J, Auriola S, Monkkonen H, Rogers MJ . The molecular mechanism of action of the antiresorptive and anti-inflammatory drug clodronate: evidence for the formation in vivo of a metabolite that inhibits bone resorption and causes osteoclast and macrophage apoptosis. Arthritis and Rheumatism 2001; 44:2201-10.

62. Rogers MJ . New insights into the molecular mechanisms of action of bisphosphonates. Current Pharmaceutical Design 2003; 9:2643-58.

63. Roel ofs AJ , Thompson K, Gordon S, Rogers MJ . Molecular mechanisms of action of bisphosphonates: current status. Clinical Cancer Research 2006; 12:6222-30.

64. Fujimura $Y$, Kitaura H, Yoshimatsu M, Eguchi T, Kohara $\mathrm{H}$, Morita $\mathrm{Y}, \mathrm{Y}$ oshida $\mathrm{N}$ :Influence of bisphosphonates on orthodontic tooth movement in mice. Eur J Orthod 2009; 31(6):572-7.

65. Liu L, I garashi K, Haruyama N, Saeki S, Shinoda H, Mitani $\mathrm{H}$. Effects of local administration of clodronate on orthodontic tooth movement and root resorption in rats. Eur J Orthod 2004; 26(5):469-73.

66. Adachi $\mathrm{H}$, I garashi $\mathrm{K}$, Mitani $\mathrm{H}$, Shinoda H.Effects of topical administration of a bisphosphonate (risedronate) on orthodontic tooth movements in rats. J Dent Res 1994; 73(8):1478-86

67. Xiong $\mathrm{H}$, Wei $\mathrm{L}, \mathrm{Hu} \mathrm{Y}$, Zhang $\mathrm{C}$, Peng B. Effect of alendronate on alveolar bone resorption and angiogenesis in rats with experimental periapical lesions. Int Endod J 2010; 43(6):485-91.

68. Tannirandorn P, Epstein S. Drug-induced bone Ioss. Osteoporos Int 2000; 11(8):637-59.
69. Russell RG, Graveley R, Skjodt H. The effects of cycl osporine A on bone and cartilage. Br J Rheumatol 1993; 32:42-6.

70. Del Pozo E, Lippuner K, Ruch W, Casez JP, Payne T, MacKenzieA, et al. Different effects of cycl osporin A on bone remodeling in young and adult rats. Bone 1995; 16(4 Suppl):271-5.

71. Erben RG, Brunner KS, Breig B, Eberle J, Goldberg M, Hofbauer LC. Skeletal effects of cyclosporin A are gender related in rats. Endocrinology 2003; 144(1):40-9.

72. Fu E, Hsieh YD, Mao TK, Shen EC. A histomorphological investigation of the effect of cyclosporinon the trabecular bone of the rat mandibular condyle. Arch Oral Biol 2001; 46(12):1105-10.

73. Shen EC, Fu E, Hsieh YD. Effects of cyclosporine A on dental alveolar bone: a histomorphometric study in rats. J Periodontol 2001; 72(5):659-65.

74. Cetinkaya BO, Acikgoz G, Keles GC, Ayas B, Korkmaz A. The effect of cyclosporine $A$ on alveolar bone in rats subjected to experimental periodontal disease. Toxicol Pathol 2006; 34(6):716-22.

75. Chen RY, Fu MM, Chih YK, Gau CH, Chiang CY, Nieh S Hsieh YD, Fu E. Effect of cycl osporine-A on orthodontictooth movement in rats. Orthod Craniofac Res 2011; 14(4):23442.

76. Angeli A, Dovio A, Sartori M, Masera RG, CeoloniB,Prolo $P$, Racca S, Chiappelli $F$. Interactions between glucocorticoids and cytokines in the bone microenvironment. Ann N Y Acad Sci 2002; 966:97-107.

77. Haraa S. AL-Shaibany Nidhal H. Ghaib Vol. The effect of glucocorticosteroid medication on orthodontically induced root resorption (An experimental study on rats). 2010; 22(1).

78. Harry MR and Sims MR: Root resorption in the bicuspid intrusion. A scanning electron microscope study. Angle Orthod1982; 52:235-58.

79. Stevnik $A$ and Mjor IA. Pulp and dentine reactions to experimental tooth intrusion. A histological study of the initial changes. Am J Orthod 1970; 57:370-85.

80. Liu Z, Xu J, EL and Wang D. Ultrasound enhances the healing of orthodontically induced root resorption in rats. Angle Orthod 2012; 82:48-55.

81. Brudvik P and Rygh P. The initial phase of orthodontic root resorption incident to local compression of the periodontal ligament. Eur J Orthod 1993; 15:249-63.

82. Brudvik $\mathrm{P}$ and Rygh $\mathrm{P}$. Transition and determinants of orthodontic root resorption-repair sequence. Eur J Orthod 1995; 17:177-88.

83. Alakus Sabuncuoglu F and Esenlik E. Influence of drugs on orthodontic tooth movement. Pakistan Oral Dent J 2010; 30:398-401.

84. Kehoe MJ , Cohen SM, Zarrinnia K and Cowan A. The effect of acetaminophen, ibuprofen and misoprostol on prostaglandin E2 synthesis and the degree and rate of orthodontic tooth movement. Angle Orthod 1996; 66:33949. 
85. Ren Y, Maltha J C, Kuijpers-J agtman A. The rat as a model for orthodontic tooth movement-a critical review and a proposed solution. European J Orthodontics 2004; 26:48390.

86. Grevstad HJ, Boe OE. Effect of doxycycline on surgically induced osteoclast recruitment in the rat. European J Oral Sciences 1995; 103:156-9.

87. Mavragani $M$, Brudvik $P$, Selvig KA: Orthodontically induced root and alveolar bone resorption: inhibitory effect of systemic doxycycline administration in rats. European J Orthodontics 2005; 27:215-25.

88. Talic NF, Evans C, Zaki AM. Inhibition of orthodontically induced root resorption with echistatin, an RGD-containing peptide. Am J Orthodontics Dentofacial Orthopedics 2006; 129:252-60.

89. Yu Wang, ShangGao, Huanj iang, PengLin, Xing-fuBao, ZhiminZhang, Min Hu. Lithium chloride attenuates root resorption during orthodontic tooth movement in rats. 2013; 468-472.

90. Frith J C, Monkkonen J, Auriola S, Monkkonen $\mathrm{H}$ and Rogers MJ. The molecular mechanism of action of the antiresorptive and anti-inflammatory drug clodronate: evidence for the formation in vivo of a metabolite that inhibits bone resorption and causes osteoclast and macrophage apoptosis. Arthritis Rheum2001; 44:2201-10.

91. Adachi $\mathrm{H}$, Igarashi $\mathrm{K}$, Mitani $\mathrm{H}$ and Shinoda $\mathrm{H}$. Effects of topical administration of a bisphosphonate (risedronate) on orthodontic tooth movements in rats. J Dent Res 1994; 73:1478-86.

92. Igarashi $\mathrm{K}$, Mitani $\mathrm{H}$, Adachi $\mathrm{H}$ and Shinoda $\mathrm{H}$ : Anchorage and retentive effects of a bisphosphonate (AHBuBP) on tooth movements in rats. Am J Orthod 1994; 106:279-89.

93. Yuji Fujimura, Hideki Kitaura, Masako Yoshimatsu, Toshiko Eguchi, Haruka Kohara, Yukiko Morita, Noriaki Yoshida. Influence of bisphosphonates on orthodontic tooth movement in mice 2009; 572-77.

94. Brugnera AJ . Atlas of laser therapy applied to clinical dentistry. Chicago: Quintessence Editora Ltda 2006.

95. Kutsch VK. Lasers in dentistry: comparing wavelengths. J Am Dent Assoc 1993; 124(2):49-54.

96. Chen RY, Fu MM, Chih YK, Gau CH, Chiang CY, Nieh S, Hsieh YD, Fu E. Effect of cycl osporine-A on orthodontic tooth movement in rats. Orthod Craniofac Res 2011; 14(4):23442.

97. Kalia S, Melsen B, Verna C. Tissue reaction to orthodontic tooth movement in acute and chronic corticosteroid treatment. Orthod Craniofac Res 2004; 7(1):26-34.

\section{Gain quick access to our journal online View our journal at www.nacd.in}

